\section{SOI: 1.1/TAS DOI: 10.15863/TAS International Scientific Journal Theoretical \& Applied Science}

\author{
p-ISSN: 2308-4944 (print) e-ISSN: 2409-0085 (online) \\ Year: 2017 Issue: $04 \quad$ Volume: 48
}

Published: 10.04.2017 http://T-Science.org
Waldemar Nowakowski

$\mathrm{PhD}$, assistant professor

Kazimierz Pulaski University of Technology and

Humanities in Radom,

Faculty of Transport and Electrical w.nowakowski@uthrad.pl

SECTION 4. Computer science, computer engineering and automation.

\title{
NETWORK MANAGEMENT SOFTWARE FOR REDUNDANT ETHERNET RING
}

\begin{abstract}
It is hard to imagine a contemporary world without tools helping in fast and efficient communication. A fundament of the modern communication is created by network infrastructure. Safety and reliability constitute main requirements for the network infrastructure, especially in the industry usage. Network technologies are helpful in achieving this condition. The author of this publication described the redundant Ethernet ring and proposed a method of the ring status control with the use of SNMP (Simple Network Management Protocol). Next, taking this method into account, the author developed network management software. In this article, the functionality of this software, with attention paid at diagnostics of the status ring, has been described. Verification of a practical method of the ring status control has proven its usefulness. It allows creating diagnostic software compatible with managed devices developed by various producers.

Key words: Network Management Software, Redundant Ethernet Ring, Reliability, Fault localization.

Language: English

Citation: Nowakowski W (2017) NETWORK MANAGEMENT SOFTWARE FOR REDUNDANT ETHERNET RING. ISJ Theoretical \& Applied Science, 04 (48): 24-29.

Soi: $\underline{\text { http://s-o-i.org/1.1/TAS-04-48-5 Doi: crossef https://dx.doi.org/10.15863/TAS.2017.04.48.5 }}$
\end{abstract}

\section{Introduction}

Ethernet network is a worldwide standard of computer networks. The Ethernet standard describes a method of connecting computers and using common cables for data transmission. Ethernet concerns data transmission on the physical layer. Network topology determines the method of mutual connection of the network hosts [15]. The most popular topology where it comes to the Ethernet standard is the star topology. In this topology, network hosts are connected to one network device, e.g. a switch [1]. An inconvenience of this solution is the faultiness of the network segment in case of a damage of a device, which is its central point [8]. A least-cost solution of this problem is using the redundant Ethernet ring topology, in which the network hosts are connected in a way so that they create a ring. At first, Ethernet did not allow to build ring topology networks. Only when the STP (Spanning Tree Protocol) (IEEE 802.1d) was developed, has it allowed to use the ring topology in Ethernet networks. On the basis of this protocol, new protocols were created, including e.g. RSTP (Rapid Spanning Tree Protocol) (IEEE 802.1w), MSTP (Multiple Spanning Tree Protocol) (IEEE 802.1s) and SPB (Shortest Path Bridging) (IEEE 802.1aq).
Additionally, network devices' producers propose their own, authorial solutions, such as Turbo Ring, Hiper Ring, Super Ring, and the like. Regardless of this, there is a problem of remote diagnostics and monitoring the network working in the redundant ring topology.

Because of the requirement of high reliability, this problem concerns mostly using the ring technology in industry. That is why manufacturers of industrial switches propose their own technological solutions and software, e.g. MXview by MOXA, Korenix NMS or HiVision made by Hirschmann. A disadvantage of these solutions is that they are designed and optimized for their own products [5]. The author of this publication has developed a universal NMS (Network Management Software), which provides the control over the redundancy Ethernet ring only thanks to the SNMP protocol.

\section{Simple Network Management Protocol}

Simple Network Management Protocol (SNMP) is a protocol for collecting and modifying information about managed network devices [10, 12]. Currently SNMP is a standard used by most manufacturers of network equipment [6]. Within this protocol there are two types of equipment: managers and agents. A computer plays a role of SNMP 


\begin{tabular}{|c|c|c|c|c|c|c|}
\hline Impact Factor: & $\begin{array}{l}\text { ISRA (India) } \\
\text { ISI (Dubai, UAE } \\
\text { GIF (Australia) } \\
\text { JIF }\end{array}$ & $\begin{array}{l}=1.344 \\
=0.829 \\
=0.564 \\
=1.500\end{array}$ & $\begin{array}{l}\text { SIS (USA) } \\
\text { PИНЦ (Russia) } \\
\text { ESJI (KZ) } \\
\text { SJIF (Morocco) }\end{array}$ & $\begin{array}{l}=0.912 \\
=0.234 \\
=3.860 \\
=\mathbf{2 . 0 3 1}\end{array}$ & $\begin{array}{l}\text { ICV (Poland) } \\
\text { PIF (India) } \\
\text { IBI (India) }\end{array}$ & $\begin{array}{l}=6.630 \\
=1.940 \\
=4.260\end{array}$ \\
\hline
\end{tabular}

manager when it runs a special program called Network Management Software (NMS) [2, 4]. A device is being managed when it runs SNMP agent. Management takes place when the NMS reads (or modifies) specific parameters, concerning the status of the device, which are stored by the SNMP agent. What is more, the agent can notify the manager about an unexpected event by sending a special message called SNMP trap, which includes information about the event. Information regarding the status of the device is being stored and shared by the agent, with the use of MIB (Management Information Base) [8, 16]. Objects are organized in a MIB base in hierarchies (tree structure). Names can be descriptive or numerical. In order to gain access to an object representing a certain resource (manager data) one needs to present all names, separated by dots, from the root to the leaf. International Organization for Standardization (ISO) is responsible for assigning names and numbers to nodes, this assures a unified nomenclature of objects.

\section{Network Management Software}

The NMS (Network Management Software), using the SNMP protocol can manage network devices which are SNMP agents [13, 14]. Thanks to the active network monitoring, it allows a quick failure diagnosis, which leads to the failure's shortening. The system is designed mostly for people who want to automatize the process of failure diagnosis and remotely configure and control the status of network devices $[3,9,11]$. The NMS allows managing network by sharing a variety of functions:

$\square$ automatic networks scanning in the search of devices (SNMP agents),

$\square$ building a network map, which would be a visualization of the network topology (including the redundancy Ethernet ring topology),

$\square$ controlling devices' work, including collecting failure alerts (SNMP traps), controlling the redundancy ring status, also notifying the user about all abnormalities via email or SMS,

$\square$ visualization of the devices' failure and the ring status,

$\square$ allowing a remote configuration and control of the status of the devices by the user as a result of reading or change of chosen parameters (MIB objects) of the SNMP agents.

The first activity during parameterization of the NMS is a network scan in order to detect devices (SNMP agents). Scanning can take place in the broadcast mode or in a defined range of network addresses. As a result of the scanning, a list of available devices is created. The main screen of the NMS with an example list of four managed switches MOXA has been presented in the Figure 1.



Figure 1 - The main screen of the NMS.

After performing the scanning, one can start building the network map. For each of the devices the user needs to point its type in order for the software to use the right graphic symbols. When the devices' symbols are put on the map, the user should link them, reproducing this way the network topology. If the ring status is to be presented in the graphic form on the map, one should additionally define the numbers of the devices' ports when linking network's nodes. The network map editor with a visualization of the ring created from four MOXA switches has been presented in the Figure 2. 


\begin{tabular}{|c|c|c|c|c|c|c|}
\hline Impact Factor: & $\begin{array}{l}\text { ISRA (India) } \\
\text { ISI (Dubai, UAE } \\
\text { GIF (Australia) } \\
\text { JIF }\end{array}$ & $\begin{array}{l}=1.344 \\
=0.829 \\
=0.564 \\
=1.500\end{array}$ & $\begin{array}{l}\text { SIS (USA) } \\
\text { PИНЦ (Russia) } \\
\text { ESJI (KZ) } \\
\text { SJIF (Morocco) }\end{array}$ & $\begin{array}{l}=0.912 \\
=0.234 \\
=\mathbf{3 . 8 6 0} \\
=\mathbf{2 . 0 3 1}\end{array}$ & $\begin{array}{l}\text { ICV (Poland) } \\
\text { PIF (India) } \\
\text { IBI (India) }\end{array}$ & $\begin{array}{l}=6.630 \\
=1.940 \\
=4.260\end{array}$ \\
\hline
\end{tabular}



Figure 2 - Network map editor with ring visualization.

The NMS manages the work of network devices by conducting several automatic control actions. One of these activities is collecting alerts (SNMP traps) from agents and informing the user about them (Figure 3). Alerts are archived in special files, which can later serve for finding the cause of the failure.

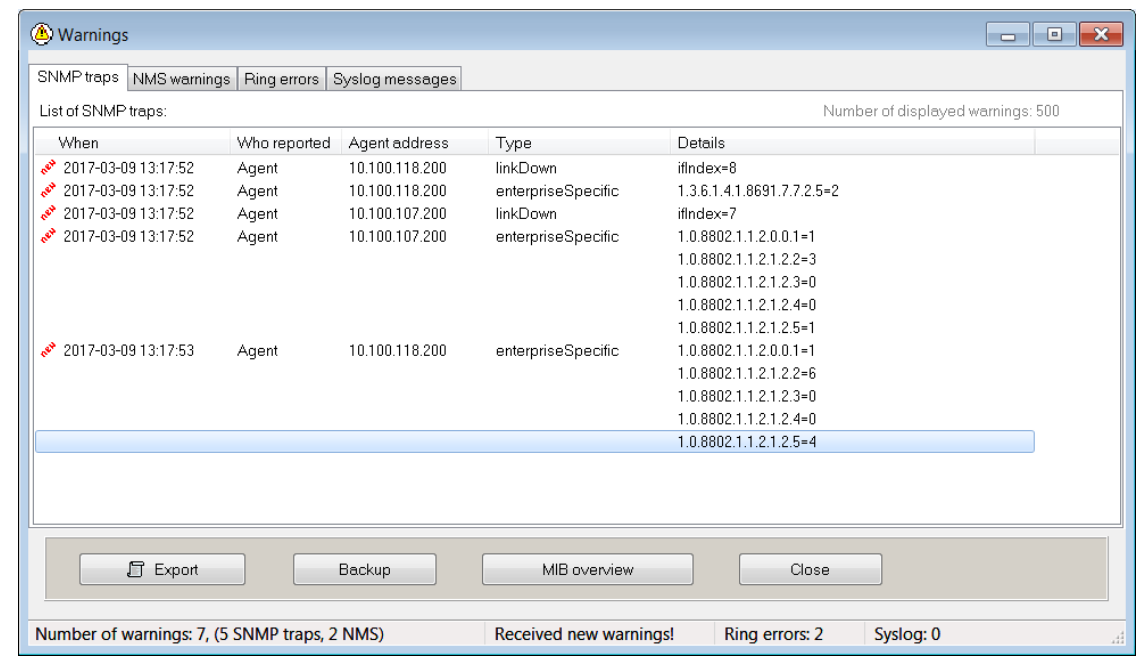

Figure 3 - A list of SNMP traps.

In order to allow the control of the redundancy ring status, the user has to additionally set in the
NMS the control of the "ifOperStatus" object of the MIB base for all ports creating the ring. 


\begin{tabular}{|c|c|c|c|c|c|c|}
\hline Impact Factor: & $\begin{array}{l}\text { ISRA (India) } \\
\text { ISI (Dubai, UAE } \\
\text { GIF (Australia) } \\
\text { JIF }\end{array}$ & $\begin{array}{l}=1.344 \\
=0.829 \\
=0.564 \\
=1.500\end{array}$ & $\begin{array}{l}\text { SIS (USA) } \\
\text { PИНЦ (Russia) } \\
\text { ESJI (KZ) } \\
\text { SJIF (Morocco) }\end{array}$ & $\begin{array}{l}=0.912 \\
=0.234 \\
=\mathbf{3 . 8 6 0} \\
=\mathbf{2 . 0 3 1}\end{array}$ & $\begin{array}{l}\text { ICV (Poland) } \\
\text { PIF (India) } \\
\text { IBI (India) }\end{array}$ & $\begin{array}{l}=6.630 \\
=1.940 \\
=4.260\end{array}$ \\
\hline
\end{tabular}

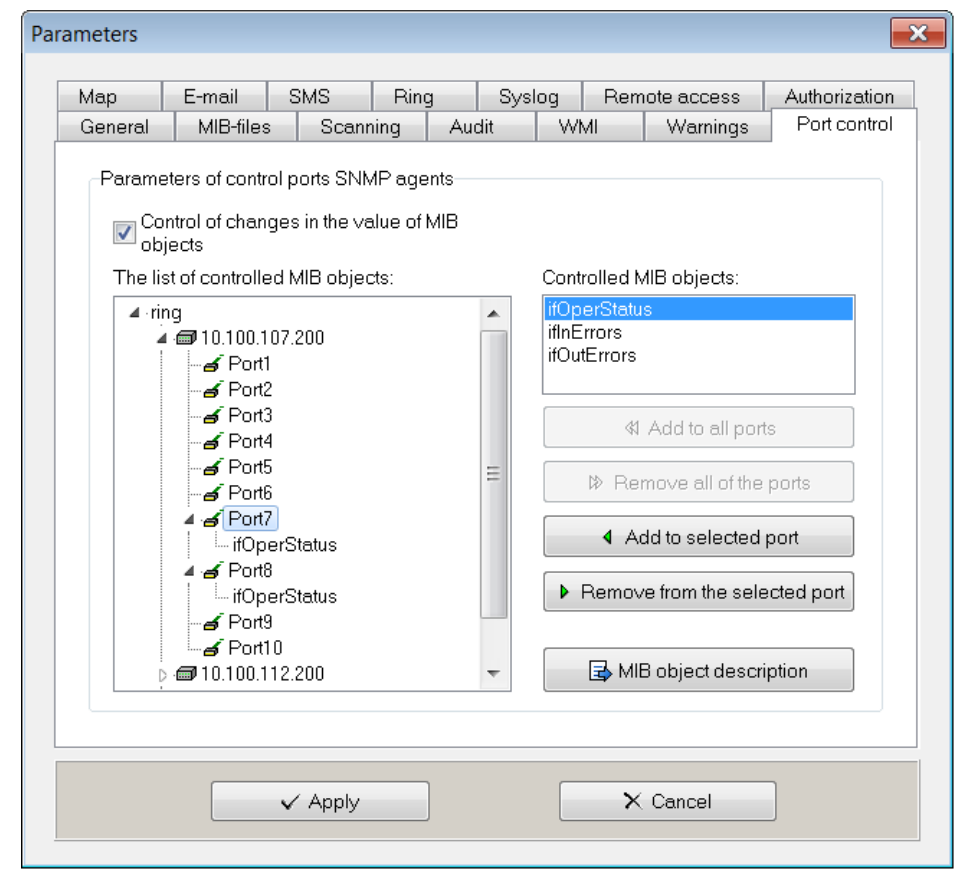

Figure 4 - Parametrization of the control of the SNMP agents' ports.

Information about a failure concerning a break in the ring is added to the failure list (Figure 3 ) and is visualized on the network map, which has been presented in the Figure 5. Additionally, all information about failures can be passed on to the user via email or SMS.

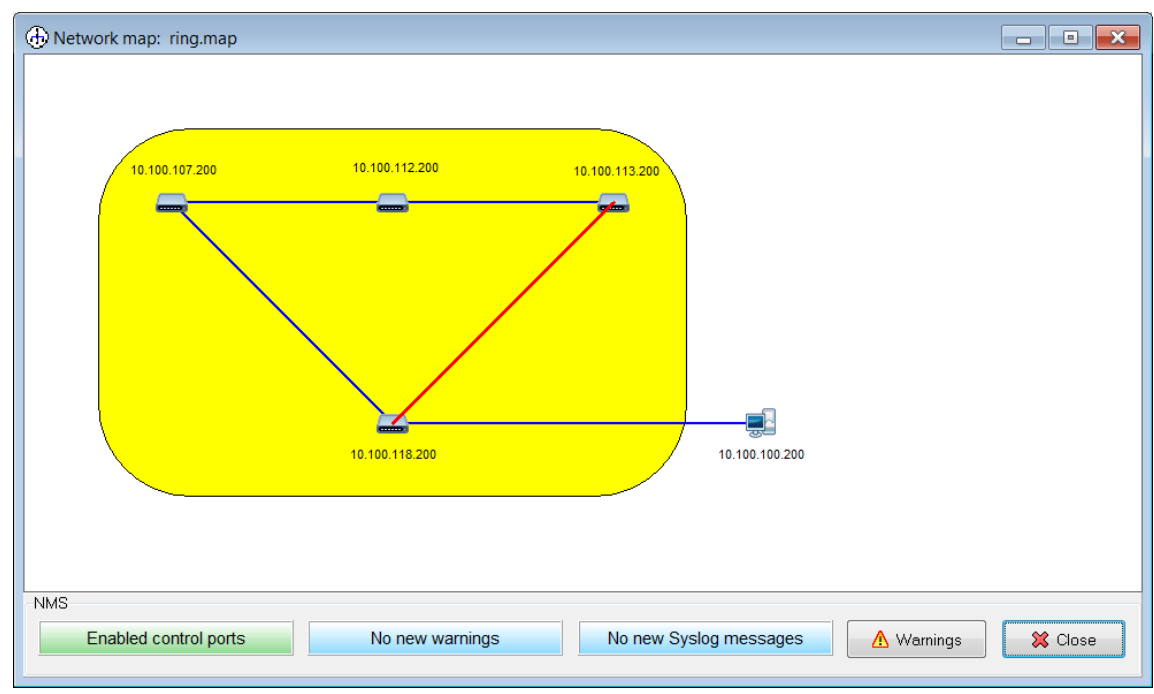

Figure 5 - An example visualization of the ring failure.

Apart from the number of automatically performed control actions, the NMS allows to control and configure devices manually. The user can look through the MIB tree, make queries about chosen agents' parameters (MIB objects) or change their value (Figure 6 and Figure 7). The NMS has the MIB compiler built-in, which allows to attach private MIB files delivered by the equipment's manufacturers. 


\begin{tabular}{|c|c|c|c|c|c|c|}
\hline Impact Factor: & $\begin{array}{l}\text { ISRA (India) } \\
\text { ISI (Dubai, UAE } \\
\text { GIF (Australia) } \\
\text { JIF }\end{array}$ & $\begin{array}{l}=1.344 \\
=0.829 \\
=0.564 \\
=1.500\end{array}$ & $\begin{array}{l}\text { SIS (USA) } \\
\text { PИНЦ (Russia) } \\
\text { ESJI (KZ) } \\
\text { SJIF (Morocco) }\end{array}$ & $\begin{array}{l}=0.912 \\
=0.234 \\
=\mathbf{3 . 8 6 0} \\
=\mathbf{2 . 0 3 1}\end{array}$ & $\begin{array}{l}\text { ICV (Poland) } \\
\text { PIF (India) } \\
\text { IBI (India) }\end{array}$ & $\begin{array}{l}=6.630 \\
=1.940 \\
=4.260\end{array}$ \\
\hline
\end{tabular}

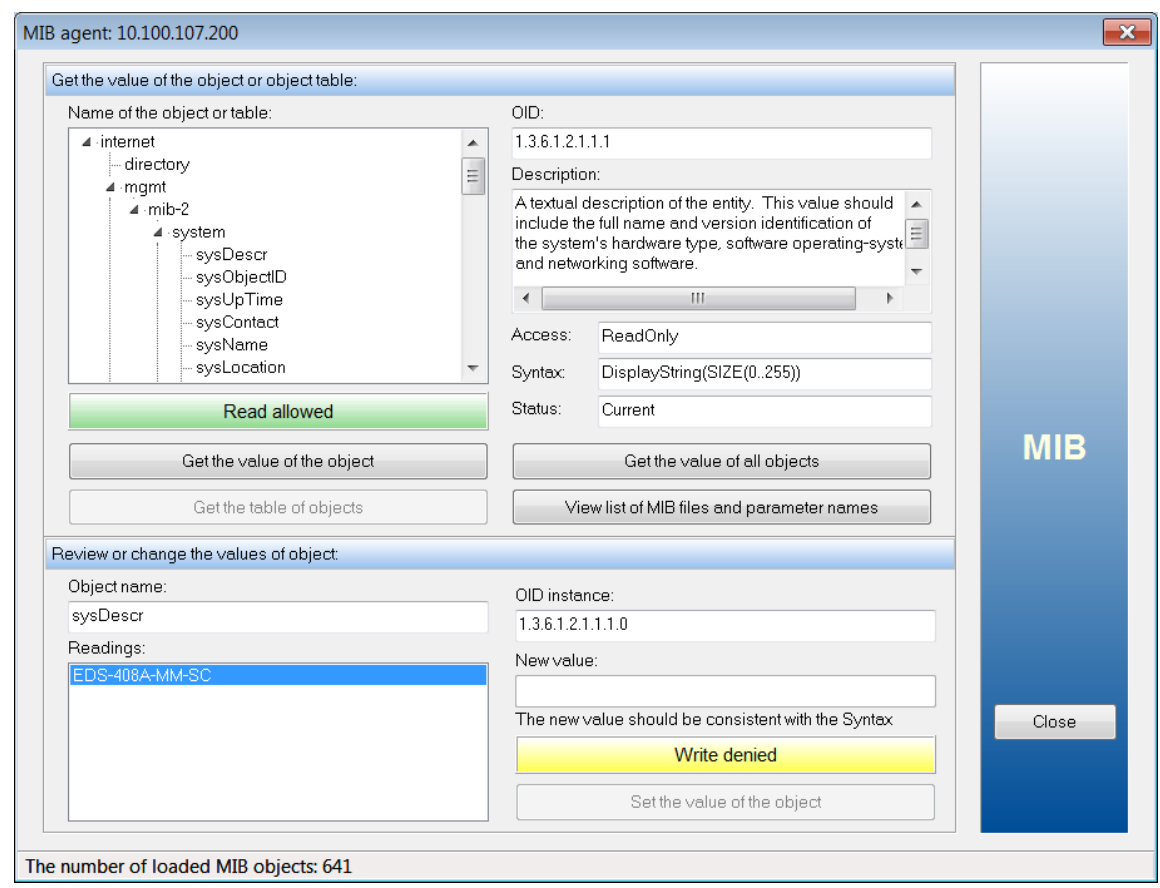

Figure 6 - SNMP MIB explorer.

\begin{tabular}{|c|c|c|c|c|c|c|c|c|c|}
\hline \multicolumn{8}{|c|}{ 可 MIB "ifTable" - Agent: 10.100.107.200 } & \multicolumn{2}{|c|}{\begin{tabular}{|l|l|}
0 & 0 \\
\end{tabular}} \\
\hline iflndex & ifDescr & ifType & iflMtu & ifSpeed & ifPhysAddress & ifAdminStatus & ifOperStatus & iflastChange & iflnOctets \\
\hline 1 & Ethernet Port 1 & ether... & 1632 & 10000000 & 00:00:00:00:00:00 & Up (1) & Down (2) & 00:00:00 (0) & 0 \\
\hline 2 & Ethernet Port 2 & ether... & 1632 & 10000000 & 00:00:00:00:00:00 & Up (1) & Down (2) & 00:00:00 (0) & 0 \\
\hline 3 & Ethernet Port 3 & ether... & 1632 & 10000000 & 00:00:00:00:00:00 & Up (1) & Down (2) & 00:00:00 (0) & 0 \\
\hline 4 & Ethernet Port 4 & ether... & 1632 & 10000000 & 00:00:00:00:00:00 & Up (1) & Down (2) & 00:00:00 (0) & 0 \\
\hline 5 & Ethernet Port 5 & ether... & 1632 & 10000000 & 00:00:00:00:00:00 & Up (1) & Down (2) & 00:00:00 (0) & 0 \\
\hline 6 & Ethernet Port 6 & ether... & 1632 & 10000000 & 00:00:00:00:00:00 & Up (1) & Down (2) & 00:00:00 (0) & 0 \\
\hline 7 & Ethernet Port 7 & ether... & 1632 & 100000000 & 00:00:00:00:00:00 & Up (1) & Up (1) & 29 days $19: \ldots$ & 34001985 \\
\hline 8 & Ethernet Port 8 & ether... & 1632 & 100000000 & 00:00:00:00:00:00 & Up (1) & Up (1) & 00:00:07 (778) & 41314297 \\
\hline 129 & Management $\mathrm{P} \ldots$ & ether... & 1500 & 100000000 & 00:90:E8:4D:7E:9A & Up (1) & Up (1) & 00:00:00 (0) & 4959429 \\
\hline 130 & (Management ... & softw... & 16384 & 0 & $00: 00: 00: 00: 00: 00$ & Up (1) & Up (1) & $00: 00: 00(0)$ & 0 \\
\hline \multicolumn{10}{|l|}{4} \\
\hline & \multicolumn{2}{|l|}{ [] Export } & & \multicolumn{2}{|l|}{ Refresh } & MIB overview & & \multicolumn{2}{|l|}{ Close } \\
\hline \multicolumn{6}{|c|}{ Table "ifTable" } & \multicolumn{4}{|c|}{ Version SNMP: 2، Read } \\
\hline
\end{tabular}

Figure 7 - Example results of the control of the "ifTable" object.

\section{Conclusion}

For many years, Ethernet has been a popular and most widely deployed network technology in the world. Small costs and easiness of implementation of this technology contribute to the fact that it is used also in industry. Because of the requirements connected to the reliability of the industrial network, very often these networks are created in the redundant Ethernet ring topology. The author of this publication has presented his own software for the management and diagnostics of the Ethernet network. In this software, among others, control of the ring status with the help of the SNMP protocol was taken into consideration. The software allows to visualize the ring status on the topology map and to notify the user about any abnormalities in the network's functioning via email or SMS. Conducted tests have proven a significant usefulness of the SNMP standard in controlling the status of the network devices, including diagnosing the ring status, regardless of the type of devices used. 


\begin{tabular}{l|lrl|l|ll} 
& ISRA (India) & $=\mathbf{1 . 3 4 4}$ & SIS (USA) & $=\mathbf{0 . 9 1 2}$ & ICV (Poland) & $=\mathbf{6 . 6 3 0}$ \\
Impact Factor: & ISI (Dubai, UAE) $=\mathbf{0 . 8 2 9}$ & PUHU (Russia) $=\mathbf{0 . 2 3 4}$ & PIF (India) & $=\mathbf{1 . 9 4 0}$ \\
& GIF (Australia) & $\mathbf{0 . 5 6 4}$ & ESJI (KZ) & $=\mathbf{3 . 8 6 0}$ & IBI (India) & $=\mathbf{4 . 2 6 0}$
\end{tabular}

\section{References:}

1. Claise B, Wolter R (2007) "Network Management: Accounting and Performance Strategies", Cisco Press, 2007

2. Duarte EP, dos Santos AL (2001) "Network fault management based on SNMP agent groups", 21st IEEE International Conference on Distributed Computing Systems, Phoenix, USA, 2001, Proceedings pp. 51-56

3. Kato N, Ohta K, Ika T, et al. (1999) "A proposal of event correlation for distributed network fault management and its evaluation", IEICE Transactions on Communications, Volume: E82B, Issue 6, pp. 859-867

4. Lu X (2009) "An Architecture for Web Based and Distributed Telecommunication Network Management System", 3rd International Symposium on Intelligent Information Technology Application, Nanchang, China, 2009, Proceedings, pp. 152-155, 2009

5. Łukasik Z, Nowakowski W (2015) „Sieciowe narzędzia diagnostyczne systemów sterowania ruchem kolejowym", Technika Transportu Szynowego (TTS) 12/2015, str. 2715-2718

6. Mauro D, Schmidt K (2005) "Essential SNMP: Help for System and Network Administrators", O'Reilly Media

7. Nowakowski W, Siergiejczyk M (2007) „System monitorowania sieci teleinformatycznych", Zeszyty Naukowe AMW, R. 48, nr 169K/1, str. 317-324, AMW Gdynia

8. Park SH, Park MS (2003) "An efficient transmission for large MIB tables in pollingbased SNMP", 10th International Conference on Telecommunications (ICT 2003), Papeete, Polynesia, 2003, 10th International Conference on Telecommunications, Proceedings, pp. 246252

9. Samba A (2006) “A network management framework for emerging telecommunications networks", Symposium on Modeling and
Simulation Tools for Emerging Telecommunications Networks, Munich, Germany, 2005, Modeling and Simulation Tools for Emerging Telecommunication Networks: Needs, Trends, Challenges and Solutions, pp. 179-200

10. Saperia J (2002) "SNMP at the Edge: Building Effective Service Management Systems", McGraw-Hill Professional, 2002

11. Sathyan J, Shenoy K, Mohan A, et al. (2007) "Developing event driven intelligent network management systems", 11th World MultiConference on Systemics, Cybernetics and Informatics/13th International Conference on Information Systems Analysis and Synthesis, Orlando, USA, 2007, 11th World MultiConference on Systemics, Cybernetics and Informatics, Volume II, Proceedings, pp. 283288

12. Stallings W (2013) "SNMP, SNMPv2, SNMPv3, and RMON 1 and 2", Addison Wesley Professional

13. Steinder M, Sethi AA (2004) "A survey of fault localization techniques in computer networks", Science of Computer Programming, Volume 53, Issue 2, pp. 165-194

14. Tang Y, Al-Shaer E, Boutaba R (2008) "Efficient fault diagnosis using incremental alarm correlation and active investigation for internet and overlay networks", IEEE Transactions on Network and Service Management, Volume: 5, Issue 1, pp. 36-49

15. Varga P, Moldovan I (2007) "Integration of service-level monitoring with fault management for end-to-end multi-provider ethernet services", Proceedings of the IEEE Transactions on Network and Service Management, Volume: 4, Issue 1, pp. 28-38

16. Walsh L (2008) "SNMP Mib Handbook", Wyndham Press. 